\title{
The emergence of marine recreational drone fishing: Regional trends and emerging concerns
}

\author{
Alexander C. Winkler (D, Edward C. Butler, Colin G. Attwood, \\ Bruce Q. Mann, Warren M. Potts
}

Received: 21 October 2020/Revised: 28 February 2021/Accepted: 16 May 2021

\begin{abstract}
Online evidence suggests that there has been an increase in interest of using unmanned aerial vehicles or drones during land-based marine recreational fishing. In the absence of reliable monitoring programs, this study used unconventional publicly available online monitoring methodologies to estimate the growing interest, global extent, catch composition and governance of this practice. Results indicated a 357\% spike in interest during 2016 primarily in New Zealand, South Africa and Australia. From an ecological perspective, many species targeted by drone fishers are vulnerable to overexploitation, while released fishes may experience heightened stress and mortality. From a social perspective, the ethics of drone fishing are being increasingly questioned by many recreational anglers and we forecast the potential for increased conflict with other beach users. In terms of governance, no resource use legislation specifically directed at recreational drone fishing was found. These findings suggest that drone fishing warrants prioritised research and management consideration.
\end{abstract}

Keywords Governance · Recreational fisheries ·

South Africa - Technology creep - Unconventional data . Unmanned aerial vehicles

\section{INTRODUCTION}

Recreational angling is an immensely popular activity globally, drawing high rates of participation (above $20 \%$ in some industrialised countries-Arlinghaus et al. 2015).

Supplementary Information The online version contains supplementary material available at https://doi.org/10.1007/s13280021-01578-y.
However, its appeal varies from person to person and is driven by a multitude of motivations which range from the acquisition of supplementary food or money (FAO 2012; Cooke et al. 2018) to the capture, and subsequent release, of fishes as personal trophies (Arlinghaus 2006; Cooke et al. 2020). As a result, recreational angling now appears in numerous different shapes and forms and targets a plethora of different fish species in a wide range of angling environments.

This profusion of recreational fisheries contributes strongly towards fish mortality globally via direct harvest as well as via the indirect death of fish following catch-andrelease (C\&R) angling (Cooke and Cowx 2004; Cooke et al. 2018). Additionally, many fish which survive C\&R may experience a multitude of negative sub-lethal impacts (Brownscombe et al. 2017). This is increasingly important as recreational fishers are driven by factors other than catch rate and profit, and therefore, have the ability to drive fish populations well below sustainable levels (Kleiven et al. 2020). However, the impacts of individual recreational fisheries are often related to the qualities of the fishers (Cooke and Suski 2005; Brownscombe et al. 2017). Thus, emerging angling methods and technologies can introduce new unrecognised threats towards fish populations (for example, see Cooke et al. (2020) perspective on 'microfishing' and Cooke et al. (2021) review of technological innovations). This is a common occurrence in commercial fisheries and termed "technology creep", whereby the use of new technologies has been attributed to increased fish catching efficiency and, in some instances, the capture a new species (Pauly and Palomares 2010). While the impacts of 'technology creep' are less well studied and appreciated within the recreational sector, they are likely to be similar (Kleiven et al. 2020). 
One such technological development amongst recreational fishers involves the use of unmanned aerial vehicles (UAVs or drones) to aid with fishing and anecdotal evidence suggests that the activity is becoming increasingly popular. This new activity is thought to be driven by the widespread popularity and easily accessible nature of highquality recreational drones (Rebolo-Ifrán et al. 2019), which have been used for a variety of applications. 'Drone fishing', as it is commonly referred to, is performed by recreational anglers who use drones to increase their fish catching efficiency. Drones are used to either transport baited lines into otherwise inaccessible areas or to perform reconnaissance and identify optimal areas for fishing including, for example, fish aggregations or essential fish habitat. While these applications have been hailed by many recreational anglers, there is also a contingent who vehemently oppose the practice based on ethical and ecological concerns (see Fig. S1). It is possible that the use of drones may have major implications for the efficacy of recreational angling, yet there is limited information on the scale, socio-economic implications and ecological consequences of drone fishing, and thus no information on important research and management needs. Especially due to our limited knowledge on the effects of technology creep within recreational fisheries.

Despite being new to fisheries science, drones have in fact been around for some time and have a number of positive applications. Importantly, drones have helped solve some common conservation problems such as policing and monitoring and multiple in-depth reviews have been published on how they are revolutionising conservation science (see: Wolinsky 2017; Nowak et al. 2019; Jiménez López and Mulero-Pázmány 2019; Butcher et al. 2021). Their use is not only making a positive impact in the fight against the illegal harvest of wildlife (Penny et al. 2019; Hambrecht et al. 2019), but they are also being used by biologists to collect a variety of data types in remote areas and on the rarest of terrestrial and marine organisms (Wolinsky 2017; Oleksyn et al. 2020). For example, drones were recently used to collect the first microbial samples from blowhole exhalent of live blue whales (Wolinsky 2017). Essentially, drones have opened up opportunities and solved common sampling problems that scientists and conservation managers would never imagined possible several years ago (Nowak et al. 2019). However, despite these positive impacts, the negative implications associated with the wide-scale use of drones are beginning to reveal themselves. Social concerns such as the invasion of privacy, noise pollution, the transport of dangerous payloads and threats to commercial aviation have been identified (Sandbrook 2015; Markowitz et al. 2017). While scientific and public safety related drone use is still considered acceptable (e.g. Stokes et al. 2020) the use of drones for recreational purposes is not well accepted by the general public, mainly because of concerns related to privacy (Wang et al. 2016; Aydin 2019). Drones may also have ecological impacts, including the disturbance of animals and birds, and there is growing concern around their use during recreational hunting (Sandbrook 2015). As drone use expands across urban and rural environments, it is likely that these social and ecological concerns will grow and diversify.

As recreational drones have only recently become available, affordable and popular (Rebolo-Ifrán et al. 2019), there are few, if any, monitoring programs on their impacts, including the impacts of drone fishing. In the absence of scientific data, recreational fisheries researchers have used tools to monitor internet search volume as a proxy for recreational fishing interest (Wilde and Pope 2013) and recreational angler behaviour (Martin et al. 2012). Others have utilised online data sources to estimate the catch volume (Belhabib et al. 2016; Giovos et al. 2018; Giglio et al. 2020), effort (Monkman et al. 2018) and catch composition (Giovos et al. 2018; Giglio et al. 2020) of various marine recreational fisheries. Similarly, ReboloIfrán et al. (2019) utilised YouTube $\subset$ video footage to understand the effects of recreational drones on terrestrial animals. On the subject of drone fishing, there is a growing body of anecdotal evidence available online through various social media platforms and in the grey literature that the occurrence of the practice is growing globally (Shea 2014; Smith 2014; Cherney 2019; FishingBooker 2020; Anderson 2021; Spires 2021, Fig. S1), which provides motivation for research.

As South African inshore recreational fisheries scientists, the authors of this study were alerted by either members of the public (Attwood and Mann pers. comm.) or specific social media discussions (See Fig. S1) relating to the potential social, ethical and ecological issues associated with marine recreational drone fishing and prompted the authors to further investigate the topic. Within the South African context, the evolution of drone fishing is highly contentious given that the inshore recreational fishery is the largest marine fishery by number of participants, largely open access, poorly governed (Potts et al. 2019) and in direct competition with subsistence, artisanal and smallscale commercial fishers (Potts et al. 2020). The inshore hook and line fishery in South Africa targets a highly diverse range of elasmobranchs and teleost species (Mann 2013). The growth of drone fishing in this complex system provides an ideal context to examine the range of socioecological consequences of the practice and this can be used to predict its potential consequences on a global scale. The aim of this study is to investigate the scale of interest in marine recreational drone fishing globally, to examine the catch composition in countries with the most active 
drone fisheries and to discuss some of the biological and ecological consequences, conservation challenges and research needs. Unconventional data sources were used to identify global trends in internet search interest in drone fishing, while catch compositions were estimated using online videos from the most important drone fishing countries. A global legislative policy review was conducted to identify whether the new activity is actively governed by any existing legislation. Lastly, evidence from social media platforms was collated with the social-ecological perspectives of South African fisheries scientists who shared their understanding of the potential consequences of drone fishing in a country where this practice is growing rapidly.

\section{MATERIALS AND METHODS}

Initial investigations into the extent and popularity of drone fishing were conducted by searching for the term "drone fishing" on prominent social media platforms until 22/07/ 2020. The number of members on drone fishing Facebook groups, the number of likes on drone fishing Facebook pages, the number of "drone fishing" videos on YouTube (C) and the number of hashtags of "drone fishing" on Instagram were recorded. This provided anecdotal evidence to gauge interest in drone fishing among social media users and whether further online investigation was needed to examine trends in this interest over time and at country level geographic scales.

Primary search term query investigations into the use of the search term "drone fishing" was conducted using ahrefs (C) (see: https://ahrefs.com) to determine the absolute search term volume on ten of the world's most popular internet search engines in 27 different languages. Further investigation into the search engine with the highest volume of searches on drone fishing was then evaluated for temporal and spatial trends.

Based on the results of absolute search term volume over the ten different search engines, it was decided that Google Trends (C) would be the most appropriate platform to investigate the temporal and spatial trends (see Table S1). Google Trends (C) provides a platform for monitoring the spatial-temporal distribution of Google search queries (see: https://trends.google.com/trends) and has been suggested to be an informative tool to monitor biological conservation issues at the desired spatial resolution (Proulx et al. 2014). Although the Google $(\mathrm{c}$ search engine is the most popular $(91 \%$ of global search engine market share (https://gs.statcounter.com/search-engine-market-share),

this, and other platforms are restricted in countries such as China, Crimea, Cuba, Iran, Myanmar, North Korea, Sudan and Syria and this methodology would thus exclude these countries. Despite this, it is likely the most inclusive methodological choice.

Google Trends (C) allows one to compare the incidence of keyword searches over time, to plot the relative search interest by country/state/city and to provide insight into events that trigger interest in specific topics. Google Trends $($ does not provide actual data on the number of searches, but rather normalises its results so that the greatest value, across regions and time, is set to 100, with all other values scaled against that observation. Google Trends $($ C was used to assess the temporal and geographic patterns in Google searches for the term "drone fishing" and its translation into 27 other languages (using Google Translate $\subset$, see Table $\mathrm{S} 1$ ). The term was run independently in each language to analyse worldwide google searches between January 2004 and August 2020. Google Trends (C identified sufficient searches for outputs in English, Spanish and Japanese and the relative number and geographic distribution of searches in these languages were compared using the Google Trends (C) 'Compare' option.

YouTube $C$ is a popular social media platform and was identified as a preferred platform to analyse drone fishing video content. To understand the composition of the drone fishing catch, the term "drone fishing" was combined with the either "New Zealand", "South Africa" or "Australia", which were the three countries with the highest search interest, and entered into the YouTube $($ C) search bar (e.g. "drone fishing" "South Africa") and sorted by relevance. Videos were then watched in descending order until 100 catch events were observed. Fish were identified to the species level. In certain instances, more than one catch event was recorded per video and certain videos displayed multiple catch events in writing at the end of the video even if it was not video-recorded. In cases where there were less than 100 catch events from a given country, as many catch events as possible were observed.

To understand global recreational drone use regulations with specific relevance to recreational drone fishing, a review was conducted on the drone law section of the UAV $\mathrm{COACH}$ website (https://uavcoach.com/drone-laws/), which is an easily accessible recreational drone user online guide. Each country's legal information was examined to identify any regulations that may directly or indirectly influence the legality of drone fishing. These included outright bans on recreational drone use, restrictions regarding the dropping of payloads (which is a prerequisite to be able to drone fish) and/or any legislation that indirectly outlaws the use of drones for recreational fishing via restrictions on other uses (such as restricted use for recreational resource acquisition-primarily aimed at hunting). If one of these regulations was mentioned, the link to the legislation was evaluated and, if needed, translated using Google Translate to cross check the information reported 
by the website. If no link to the legislation was found or it was inaccessible, the information was assumed to be correct. If there was no evidence of any regulation that may influence the legality of recreational drone use, the country was not listed in the meta-analysis and it was assumed that recreational drone fishing is legal.

\section{RESULTS AND DISCUSSION}

\section{Preliminary social media analyses}

The preliminary social media search provided evidence to suggest interest in drone fishing with a relatively large number of members belonging to "drone fishing" Facebook groups (up to 17481 ) and a large number of likes for "drone fishing" Facebook pages (up to 86477 ) (Table 1). This was despite the recent establishment of these groups (2015 and later). The geographical distribution of these groups were predominantly focussed around Australasia and South Africa, although there was a European group and several global groups with a broad geographical membership (Table 1). Further support for the popularity of drone fishing was observed on Instagram, where hashtags for the term "drone fishing" totalled 7807, and on YouTube, where 38700 videos with titles including the term "drone fishing" had been uploaded. While these preliminary searches suggested that there was a great deal of interest in drone fishing in certain areas, it was not possible to ascertain if there had been a recent increase in drone fishing interest.

\section{Global search volume}

Absolute search term volumes varied amongst the ten different search engine platforms and the 27 different language translations of "drone fishing" that were assessed. Only the languages English, Spanish, Japanese and French returned results where there was a search volume of $>10$ searches per month. Google $\subseteq$ was the only platform on which searches were conducted in all four of these languages followed by YouTube $\odot$ where searches were

Table 1 Summary table outlining the popularity of drone fishing on Facebook@ and Instagram $\subset$ using related posts or pages containing the words "drone fishing". Metrics denote the number of Facebook $\odot$ page likes, Facebook $₫$ group members and the number of times a hash tag was posted on Instagram (C) as of $22 / 07 / 2020$

\begin{tabular}{|c|c|c|c|c|c|}
\hline Platform & Name & Region or country & Date established & Type & Indicator \\
\hline & & & & & Members \\
\hline Facebook & Drone Fishing Community & Global & 2016 & Group & 17481 \\
\hline Facebook & Drone fishing ANZ & Australisia & 2019 & Group & 7100 \\
\hline Facebook & Drone Fishing Australia & Australia & 2015 & Group & 3634 \\
\hline Facebook & Sky Anglers-Drone fishing & Global & 2017 & Group & 3280 \\
\hline Facebook & Perth Drone Fishing & Australia & 2018 & Group & 2026 \\
\hline Facebook & Drone Fishing HQ & Global & 2017 & Group & 1861 \\
\hline Facebook & Drone Fishing & Global & 2018 & Group & 1728 \\
\hline Facebook & Drone Fishing RSA & South Africa & 2017 & Group & 524 \\
\hline Facebook & Drone Fishing 808 & Global & 2016 & Group & 515 \\
\hline \multirow[t]{2}{*}{ Facebook } & Drone Fishing Europe & Europe & 2017 & Group & 115 \\
\hline & & & & & Likes \\
\hline Facebook & Drone Fishing-Gannet & Global & 2016 & Page & 86477 \\
\hline Facebook & Cuta Copter Fishing Drones & Global & 2015 & Page & 5871 \\
\hline Facebook & Drone Fishing with Cuta-Copter & Global & 2017 & Page & 2175 \\
\hline Facebook & Drone Fishing International & Global & 2017 & Page & 2061 \\
\hline Facebook & Drone Fishing & Global & 2016 & Page & 432 \\
\hline Facebook & Drone Fishing Texas & USA & 2017 & Page & 380 \\
\hline \multirow[t]{2}{*}{ Facebook } & Fish on Drone & Global & 2019 & Page & 113 \\
\hline & & & & & Hash-tags \\
\hline \multirow[t]{2}{*}{ Instagram } & \#dronefishing & Global & NA & NA & 7807 \\
\hline & & & & & Video uploads \\
\hline YouTube & "Drone Fishing" & Global & NA & NA & 38700 \\
\hline
\end{tabular}


conducted in English, Japanese and Spanish. Searches in English made up the majority across all the platforms and equalled 14750 searches per month, of which 8400 were conducted on YouTube $\odot$, 5100 on Google $\odot$ and 150 or less on the remaining search engines (See Table S1).

\section{Global search trends (Google trends $₫$ )}

English searches for "drone fishing" dominated the google searches $(80.6 \%)$, followed by searches in Japanese $(12.4 \%)$ and Spanish (6.9\%). There was a clear trend in the number of worldwide searches for "drone fishing" (and its translations) with a relatively low number of searches before 2014 followed by a spike in internet searches observed in May 2016 (Fig. 1). When the term "drone fishing" was searched between the 1st of April and 31st of May 2016, it was clear that this spike in searches was the result of a "viral" YouTube $\odot$ video which was posted on the 28th of April 2016 showing an Australian angler capturing a longfin tuna (Thunnus alalunga) off the beach near Tweed Heads, New South Wales, Australia. This video has received over 5 million views on YouTube (c) (as of 25/08/ 2020), and countless more via other social media outlets. This video appeared to herald the beginning of a period where searches for drone fishing increased by $357 \%$ when compared with average searches a year prior. With the current global monthly Google $\odot$ search volume into drone fishing (February 2021) being 5100 searches per month (Table S1), this equates to an approximate absolute search volume increase of $\sim 3600$ monthly searches from an average of $\sim 1400$ before the peak. This growth and extent of interest in drone fishing not only highlights the increased interest in this new fishing method, but also the power of social media as a global communication tool and, consequently, an important data mining tool for conservation scientists (Toivonen et al. 2019). Recreational fishing related social media pages and groups on Facebook $\odot$,
Whatsapp $₫$, Instagram $\odot$ and other platforms are all capable of quickly disseminating information on new technology and techniques that improve the efficacy of recreational angling (Maggs et al. 2016). These types of rapid changes should be a major concern for fisheries managers, and it is recommended that they should maintain a presence on recreational fishing social networks.

In terms of geographic distribution, relative searches for the term "drone fishing" (or its translation) were predominantly made from New Zealand (highest-100), South Africa (80) and Australia (75), followed, to a lesser extent, by Japan (15), the United States (12) and Greece (11), although searches were conducted from a further 11 countries in almost all major continents (relative interest $<10$ ) (Fig. 2). This was supported by the analysis of social media content which was dominated by posts and pages made by recreational anglers from New Zealand, South Africa and Australia (Table 1). This suggests that fisheries managers in these countries should pay particular attention towards understanding the social-ecological impact of this new sector, while other less-prevalent countries should likely monitor the growth of the activity. Additionally, due to the methodological limitations of this study, fisheries managers in countries where Google $\odot$ is either restricted or unpopular should also monitor for the growth of the sport.

A total of 100 catch events were observed on YouTube $\odot$ videos for New Zealand and Australia, while 62 were observed for South Africa. New Zealand drone anglers landed the fewest species (4), consisting of only teleosts and dominated by Australasian snapper (Chrysophrys auratus) (76\%) (Fig. 3). Australian drone catch was the most diverse (20 species) and, although it was dominated by elasmobranchs $(58 \%)$, the most commonly caught species was also C. auratus (24\%), followed by the grey gummy shark (Mustelus ravidus) (16\%) and Australian eagle ray (Myliobatis australis) (11\%) (Fig. 3).

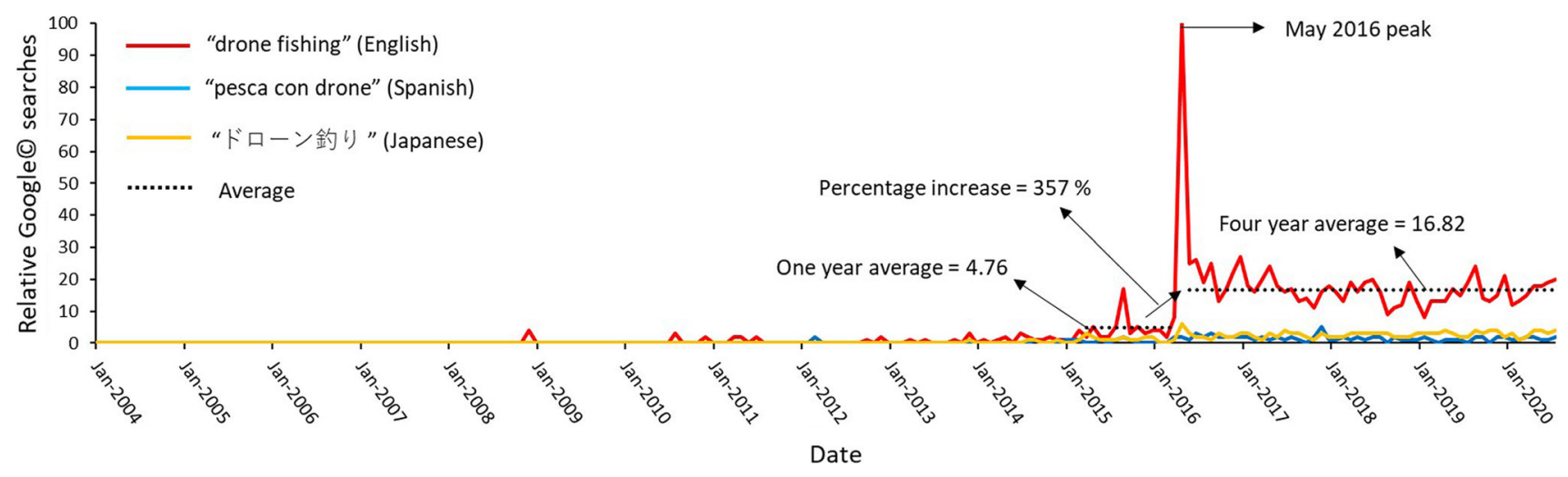

Fig. 1 Relative online Google search interest in the terms “drone fishing”, “pesca con drone” and “ドローン釣り” between 2004 and 2020. Dotted lines represent either the single year average between April 2015 and April 2016 and the 4-year average between June 2016 and August 2020 


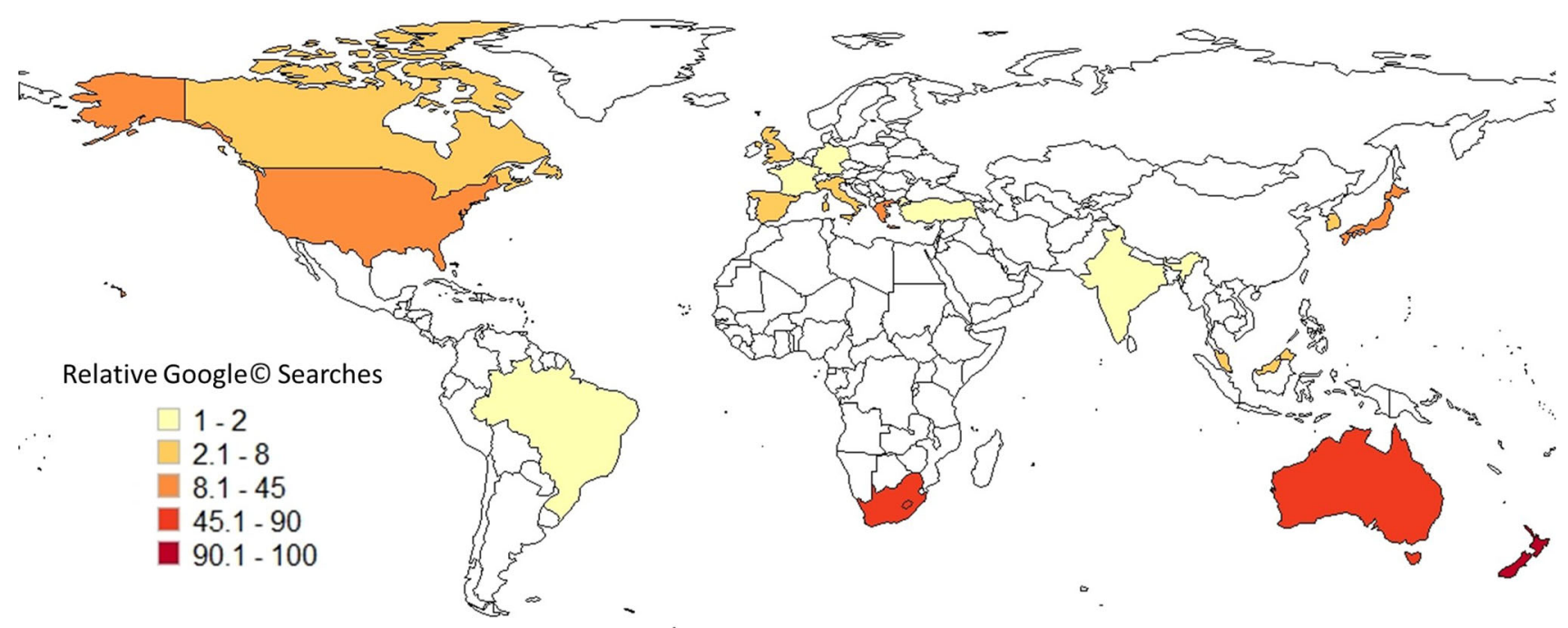

Fig. 2 Geographically referenced Google Trend ${ }^{\circledR}$ search term data for the search terms "drone fishing” (English), "pesca con drone" (Spanish) and “ドローン釣り”(Japanese). Data is scaled to the highest single country result

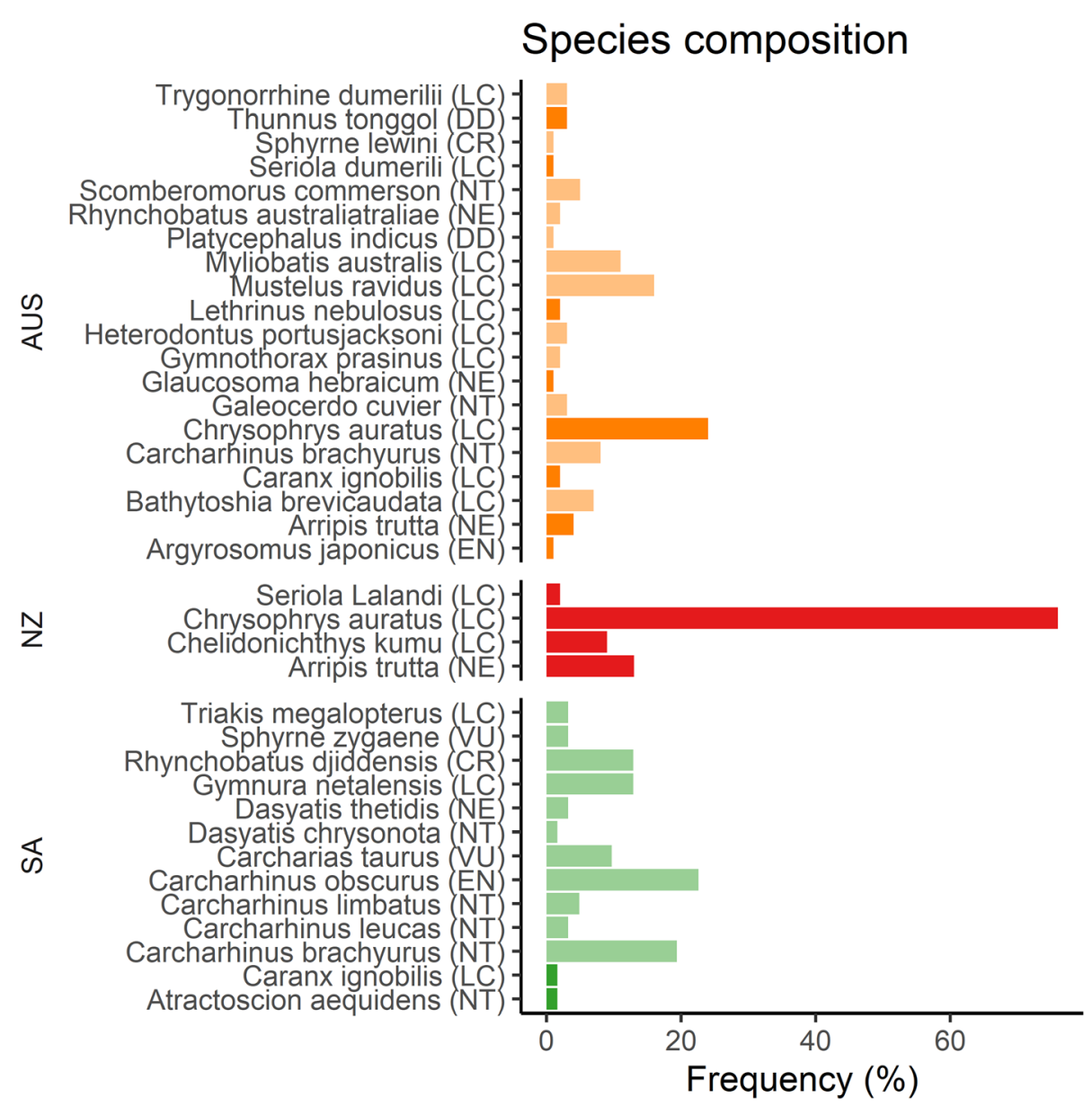

Fig. 3 Species composition and associated percentage frequency of drone fishing catch events observed in YouTube $\subset$ video footage by recreational anglers for the three countries with the highest online drone fishing interest. AUS = Australia, NZ = New Zealand and SA $=$ South Africa. Abbreviations in parenthesis refer to each species' global IUCN Red List conservation status (NE): Not Evaluated, (LC): Least Concern, (NT): Near Threatened, (VU): Vulnerable, (EN): Endangered, (CR): Critically Endangered. Light and dark shaded bars correspond to Elasmonbrach and Teleost fishes respectively 


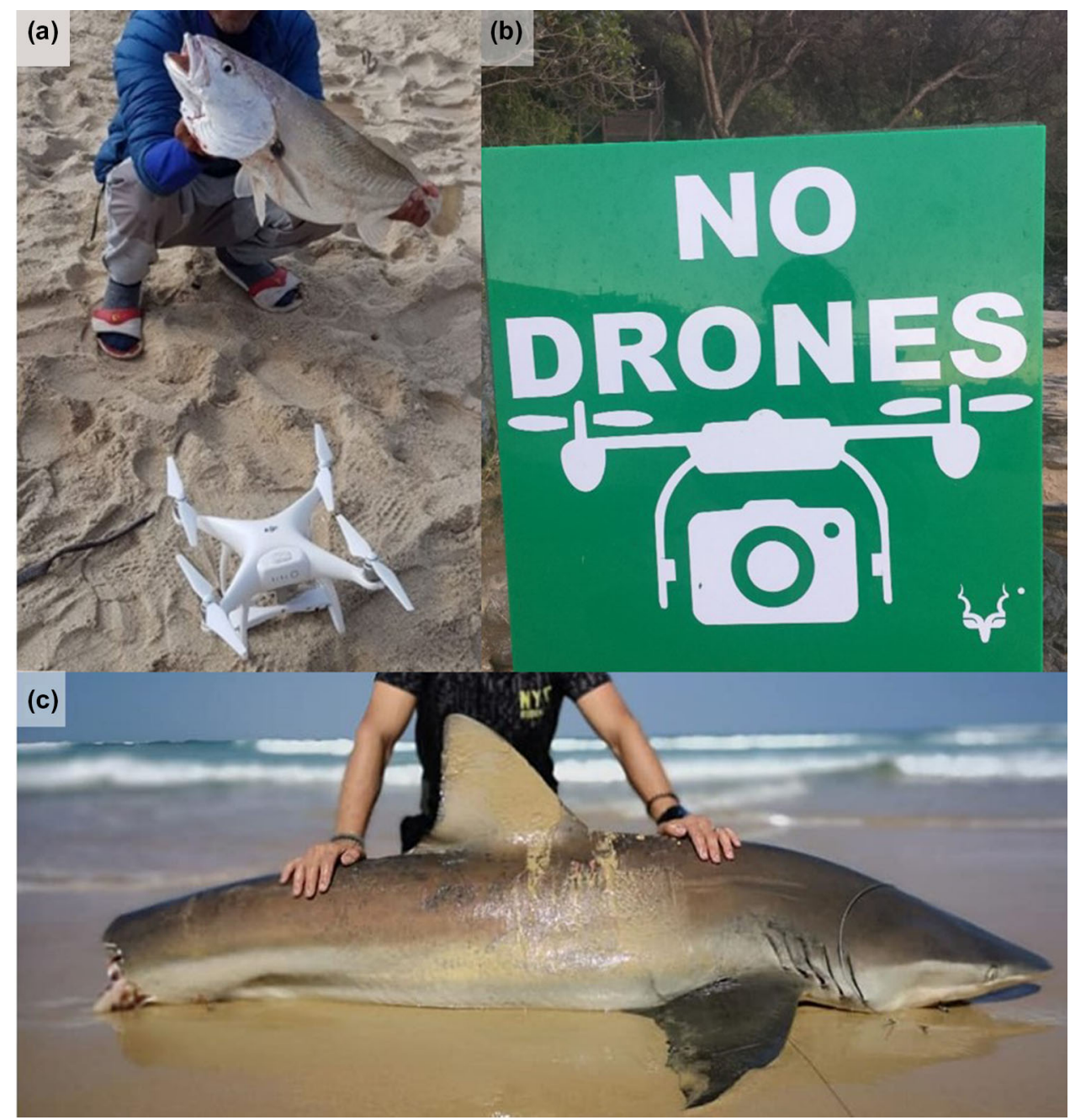

Fig. 4 Drone fishing related images scraped off social media sites showing a Argyrosomus inodorus captured using a drone, $\mathbf{b}$ signage exhibiting the prohibition of drone flying within a South African national park and $\mathbf{c}$ a drone-caught Carcharhinus brachyurus showing clear signs of depredation

South African drone catch was dominated by large elasmobranchs (97\%) (Fig. 3) including the dusky shark (Carcharhinus obscurus) (23\%), bronze whaler shark (Carcharhinus brachyurus) (19\%) and butterfly ray (Gymnura natalensis) (13\%) (Fig. 3).

Of the main target species, there is already some concern about the stock status of $C$. auratus in Australian waters (Wortmann et al. 2018). Further development of this fishery, via drone fishing, may place this species under additional pressure. Of greater concern, however, is the high percentage of IUCN Red Listed species observed in the drone catch, particularly in South Africa (69\%). Of these, a high proportion are large elasmobranchs. This is very concerning, especially due to the negative repercussions of angling on shark physiology, behaviour, fitness and survival (Skomal 2007; Gallagher et al. 2017).
Mortality from this fishery may have considerable impacts as large elasmobranchs are extremely vulnerable to exploitation (Queiroz et al. 2019). In particular, the capture of Endangered dusky sharks, Carcharhinus obscurus, and Critically Endangered whitespotted wedgefish, Rhynchobatus djiddensis, which together comprised $35 \%$ of the drone catch in South Africa (Fig. 3), is most concerning.

From the review of policy and legislation globally, there was no evidence of any law which has been specifically created to prohibit or restrict the use of drones for the purpose of recreational fishing. However, there were a number of instances whereby drone fishing may be restricted indirectly via other existing law. For example, legislation developed for many protected areas (see Fig. 4b) (Nowak et al. 2019) commonly prohibits the use of drones due to the unnatural disturbance they have on 
wildlife (Bennitt et al. 2019; Rebolo-Ifrán et al. 2019), with emphasis made on their effects on bird populations (Borrelle and Fletcher 2017). Similarly, recreational drone use is commonly prohibited near high security areas such as airports or army bases, based on their ability to collect classified information and their potential threat to human safety. They are also considered to be sources of noise pollution and a threat to personal privacy (Sandbrook 2015; Wang et al. 2016; Markowitz et al. 2017; Aydin 2019), and new legislation may restrict their use in areas where drones may infringe on the rights of other people (e.g. popular beaches).

Drones have also been prohibited for extractive natural resource use in a few parts of the world (Table S3). This legislation has primarily been developed to regulate the use of drones for recreational hunting, where drones are largely used as a reconnaissance tool to spot target animals and plan angles of approach. Drones are particularly effective when used to spy on large mammals that have evolved without airborne predators. For example, larger ungulates such as deer have been shown to almost ignore overhead drone activity (Barasona et al. 2014). This has sparked ethical debate around the use of drones for hunting large mammals among recreational hunters in the USA (Sandbrook 2015) and has contributed to the prohibition of drones for hunting purposes in many American states and certain European countries (Table S3). As much of the legal hunting legislation in the United States is broadly linked to recreational fishing, as they are both grouped as extractive recreational activities, prohibitive laws generally apply to both recreational hunting and fishing. Similarly, drone use as a hunting tool has been outlawed in parts of Canada (British Columbia), Sweden and Switzerland (see Table S3).

Ethical debates surrounding the use of drones during recreational fishing are becoming increasingly common (Fig. S1) and are often related to the 'unfair advantage' that they provide, both when transporting baits and performing reconnaissance. However, they have not yet resulted in any directed policy change. This is most likely because technological advances in recreational fishing have largely gone undetected by management and research and are therefore seldom recognised. For example, advances such as low diameter, high-strength braided fishing lines, nextgeneration fish finding sonar devices and electronic reels have all become commonly used tools within recreational fisheries, with little to no response from management or researchers (Kleiven et al. 2020) until recently (Cooke et al. 2021).

Increased drone presence in coastal areas is likely to result in increased conflict between different user groups. For example, when investigating the potential use of drones as a shark detection measure on Australian beaches, Stokes et al. (2020) found that users' primary concern was that of an infringement on their privacy. Although the number of concerned users was low (7\%), the use of drones in this study was directly beneficial to beach users and there was the assurance that drones would be piloted by trained individuals for the strict purpose of preventing shark attacks. Conversely, this would not be the case with recreational fishing drones as pilots may not be trained and their activity is not always obvious to other beach users or in any way beneficial to their safety. Therefore, privacy issues are likely to be more of a concern. Given the increased use of drones for fisheries reconnaissance and the rapid advances in these types of technologies, we may not be far from a time where drones could be used to continually monitor and broadcast live information on fish distribution and fishing conditions to recreational anglers through the internet. This will naturally provide further privacy concerns to other public beach user groups.

\section{Perspectives on drone fishing from experiences in South Africa}

\section{Ecological concerns about drone fishing}

There are several ecological concerns that have been raised about drone fishing in South Africa. One of the largest concerns is that it may eliminate the few remaining refugia that resident fishes may have. For example, the silver kob, Argyrosomus inodorus in the Western Cape of South Africa is now targeted in areas that are beyond the reach of casting shore anglers and nearer to shore than boat-based fishers could safely operate along this high energy coastline (Fig. 4a). This should equally apply to coastal resident species in other parts of the world, such as Chrysophrys auratus in Australia and New Zealand (Harasti et al. 2015). Resident species are often overexploited and drone fishing may now allow anglers access to specific fish population 'ecotypes' (Knutsen et al. 2018) which have historically been protected. Additionally, drones may also allow anglers to identify ideal fishing areas as well as fish far from the shore in areas that are exempt from boat fishing activity, as they may be long distances away from launching sites, and this will place new ecotypes under exploitation pressure. However, there are also limitations to the use of drones, such as the weight of the equipment, which reduces angler mobility and the reduced capabilities of drones in windy conditions (although the technology is improving rapidly). Thus, identifying, assessing and managing individual drone fishing hotspots and their target species will likely be necessary for assessing the impacts of drone fishing.

While the removal of previously protected ecotypes may seem trivial, for some vulnerable species, such as $A$. 
inodorus, the stock of which has been assessed as collapsed in South Africa (Winker and Silva 2017), this is a real concern. Shore-based catches of this species appear to be spiking in certain areas for the first time in decades and this can most likely be attributed to drone fishing (Attwood pers. obs.). While the capture of this species was not documented in the YouTube (C) analysis (see Fig. 3), likely due to its controversial nature, anecdotal evidence submitted to fisheries scientists in the Western Cape, South Africa by concerned fishermen has been validated. The areas targeted by drone anglers are sandy, shallow surf habitats that extend great distances out to sea. The sand banks situated further from the shore that were inaccessible from either land or boat are now successfully exploited by drone fishermen to the further detriment of the population. Additionally, drones allow anglers an aerial view of the area, allowing them to choose the ideal spot to target. Technology creep such as this often give anglers a false impression regarding the health of fish stocks. They may also skew catch rate data used in stock assessments and lead to hyperstability (Erisman et al. 2011; Maggs et al. 2016). This occurs when a misinterpretation of increases in catch is wrongly equated to an increase in fish abundance (Rose and Kulka 1999).

Although the effects of drone fishing on fish stocks is obviously greatest when the targeted fishes are captured and killed, a substantial proportion of recreational catches are released. This is because recreational angling often makes use of catch-and-release (C\&R) to comply with fishery regulations (i.e. bag and size limits) or to promote the voluntary conservation goals of anglers. Additionally, certain trophy species are not desirable food-fish and are therefore almost exclusively released (e.g. large elasmobranchs). Regardless of the reasoning, it is critical that released fishes maintain minimal ill-effects and display maximum rates of survival. However, C\&R can have major deleterious effects on fishes via related physiological impairment and, on occasion, mortality (Brownscombe et al. 2017). This may be particularly relevant for drone fishing due to the large size of the target fish and the great distances over which they are retrieved. Concerns about the post release mortality of elasmobranchs captured in the drone fishery have already been expressed by the responsible management agency (da Silva et al. 2015).

A major contributing factor towards the impairment and mortality of released fishes, and one which is particularly relevant for drone fishing, is the exhaustion associated with long 'fights'. Extended fight times can result in motor impairment and physiological stress in both sharks (e.g. Gallagher et al. 2014) and teleosts (e.g. Brownscombe et al. 2015) and can increase the rate of C\&R-related mortality (e.g. Moxham et al. 2019). It is also possible that drone fishing may contribute towards increased C\&R mortality via depredation (Raby et al. 2014). Depredation of hooked fishes is common during angling (Moxham et al. 2019; Holder et al. 2020), and extended fights, which are commonly associated with drone fishing, may increase its likelihood (Mitchell et al. 2018) both during angling and post-release. In our social media searches, we found evidence of drone fishing depredation in several posts (Fig. 4c) as well as in at least one of the YouTube (C) videos (e.g. Table S2). While the consequences of C\&R are often highly context dependent, the implications of hooking large fishes hundreds of meters offshore, are likely to be extreme exhaustion, physiological disturbance and, on occasion, depredation.

Potential loss of fishing tackle by drone anglers is also concerning. During angling, it is common to lose tackle when terminal tackle gets stuck in rocky habitat. Additionally, tackle failure, such as line breaks are common while fighting large fish such as sharks. Both scenarios may result in hundreds of meters of fishing line being left in the ocean which poses a number of threats including the entanglement of birds, marine mammals and turtles (Yoshikawa and Asoh 2004; FAO 2012; Ryan 2018) and pollution of the environment (Derraik 2002). Understanding whether drone fishing does indeed increase the amount of recreational fishing associated debris left in the ocean is an important question that needs to be investigated given the severity of the issue globally (Derraik 2002).

\section{Governance of South African drone fishing}

Although drone fishing is not specifically regulated by the Marine Living Resources Act (MLRA 1998) in South Africa, there is other legislation that indirectly relates to the practice. For example, the national Civil Aviation Authority law states that permission is needed to drop a payload from any drone (Table S3). Additionally, commercial drone use is only permitted by licenced drone pilots (Table S3). Although not strictly applicable to recreational anglers, commercial drone use would apply to professional South African angling guides. It would also apply to recreational drone pilots who facilitate drone fishing by charging conventional shore anglers a fee to drop their baited hooks further offshore from certain South African beaches (Attwood pers. obs.). Despite the presence of relevant legislation, there appears to be little knowledge of these regulations among drone anglers or fisheries management authorities and, to our knowledge, no enforcement. As the legislation governing recreational drone use in most countries, including South Africa, is relatively new, its interpretation will likely be decided in a court of law on a case-by-case basis.

Another regulation which is relevant to drone fishing can be found in the National Environmental Management 
Act (1998) that prohibits the use of drones 2500 feet below the highest point of any national park, without the permission of the South African National Parks management authority. However, there is anecdotal evidence suggesting that recreational drone fishermen are dropping baits inside marine protected areas from surrounding unprotected areas (Mann pers. obs.). This practice is concerning as it will erode the integrity of these areas and have negative ecosystem impacts.

\section{Socio-economic considerations of drone fishing}

Drone fishing may provide considerable socio-economic benefits and may broaden the scope of participation in recreational angling. For example, drone fishing allows those that are incapable of casting to participate in recreational angling. This was evident from the YouTube $\odot$ video analysis where multiple videos were posted by a single paraplegic angler in New Zealand. Not only does this bolster participation but may provide social and selfimprovement benefits for anglers with disabilities (Freudenberg and Arlinghaus 2009) and may provide opportunities for the development of disability support groups (see comments in Table S2). Additionally, while drones are expensive, their associated costs are small and their operation is considerably safer when compared with small sea-going vessels, which are considered to be the most hazardous vessels with the highest rate of occupational mortality in the fishing industry (Montero and Pulido 2012). Therefore, although not specific to recreational angling, it is possible that viable small-scale drone fishing enterprises could be developed (in specific circumstances). However, a full experimental procedure is recommended to first examine the social-ecological sustainability of such ventures.

The burgeoning drone fishery has already created employment opportunities. Dedicated waterproof fishing drones and the tackle associated with them are being developed and marketed in a global tackle industry trade which is worth billions of USD\$ (Cisneros-montemayor and Sumaila 2010). It is likely that this industry will grow and provide additional opportunities, including some for local innovation.

While there may be several social benefits associated with drone fishing, there are also a number of potential challenges. South Africa has a dualist economy and while there are wealthy individuals associated with the capitalist economy, much of the population is extremely poor (Bojabotseha 2011). Currently, with the high costs of drones and the technical capabilities required to operate these vehicles, drone fishing is only accessible to affluent recreational anglers. However, many of the species targeted by these recreational anglers (e.g. A. inodorus) are also targeted by small-scale/subsistence fishers that fish primarily for food security (Branch et al. 2002). It is likely that the increase in efficiency of recreational anglers (through drone fishing) will decrease the ability of subsistence and small-scale fishers to maintain their livelihoods. Additionally, increases in recreational fishing participation and effort is concerning as the large, open access recreational fishery already imposes considerable pressure on South African fish stocks (Potts et al. 2020).

Ethical conflict surrounding drone fishing in South Africa is also concerning. A growing proportion of recreational anglers are questioning the ethics and ecological consequences surrounding the use of drones, either because they provide anglers with an unfair advantage or because they are concerned about the potential ecological consequences of the practice, many of which have been highlighted previously (see Fig. S1). There is also a concern, particularly among the more skilled anglers, that drone fishing levels the playing field by eliminating the need to be able to cast long-distances with large baits. This conflict will likely grow over time and, like all fisheries conflicts, can negatively impact the complex social-ecological system within which recreational fisheries operate.

\section{CONCLUSIONS}

Regardless of the current legality of drone fishing in various parts of the world, its potential effects need to be adequately researched, understood, and accounted for by fisheries stakeholders, managers and conservationists. Is there really cause for concern or can drone fishing be viewed as part of the natural evolution of sustainable recreational fisheries practices? Currently, from sources on social media and in the grey literature there is much ethical debate regarding the practice (Shea 2014; Smith 2014; Cherney 2019; FishingBooker 2020; Anderson 2021; Spires 2021, Fig. S1). Given the largescale impacts of many recreational fisheries, it is important that we begin monitoring and controlling their ever-increasing fishcatching efficiency, which is often more strictly regulated in other sectors. The unconventional data sources used in this study successfully provided some perspective on the use of drones in recreational fisheries. This not only highlights the value of alternative data sources to fisheries researchers, particularly when there are no monitoring or data collection programs in place, but also that drone fishing urgently requires research and management consideration. Our findings suggest that although there is a place for drones in our current society, particularly as important tools to combat common ecological and conservation problems (see Nowak et al. 2019), we should not underestimate their potential to counteract the very issues 
Table 2 Suggested ecological and social research and monitoring priorities that need to be considered to sustainably manage the growing popularity of marine recreational drone fishing

Priority
Ecological research and monitoring priorities
Monitor participation and effort in drone fishing

Monitor drone fishing catch composition

Assess health and post release survival of fishes targeted by drone anglers

Identify fish ecotypes that may be susceptible to drone fishing

Assess other ecosystem impacts of drone fishing

Social research and monitoring priorities

Obtain an understanding of the policy and regulatory framework surrounding the use of drones

Understand the human dimension of drone fishing

Monitor inter and intra-sectoral conflict

Understand the economic advantages associated with drone fishing

\section{Strategy}

It was clear from this study's findings that recreational angler behaviour can rapidly change. Managers should therefore maintain a proactive approach and monitor the participation and effort distribution of drone fishing

This study revealed that vulnerable species were targeted in many parts of the world. Additionally, the South African case study suggested that the emerging drone fishery is likely to compete for resources with livelihood fisheries. Therefore, to ensure the protection of vulnerable and important dual-fishery species, it will be essential to monitor catch in this fishery

Due to the targeting of large sharks and fishes far distances from shore, it is likely that drone fishing will result in the increased physical and physiological stress of caught fishes and may increase rates of direct and indirect C\&R-related mortality. However, as the impacts of $\mathrm{C} \& \mathrm{R}$ fishing are context specific, impacts should be investigated locally

It is possible that previously unexploited components of fish populations may be more susceptible to exploitation by drone anglers. This may have considerable ecological and evolutionary consequences and should be assessed

The loss of fishing tackle and particularly monofilament and braided line is a concern for a range of marine animals. The potential for line-loss should be assessed and line-loss should be monitored within the sector. Drone disturbance on other marine fauna (such as birds) should too be monitored given the evidence from other studies which suggest that drone disturbance can be significant on a variety of fauna

This should specifically focus on how these relate to drone fishing. As in the case of South Africa, this may include careful examination of the policies pertaining to natural resource use, aviation and protected areas

Recreational anglers may use drones for a variety of reasons. Thus, assessing angler motives, preferences and behaviours will be necessary to better understand the likely biological impact of the emerging sector and improve its management

It is likely that the growth of drone fishing will result in inter-sectoral fisheries resource conflict and intra-sectoral ethical conflict between drone fishers and other littoral zone users. Managers should be aware of likely conflicts and monitor them as they may have social-ecological consequences.

Understanding the current size of the industry as well as understanding how big the drone fishing economy is will be an important factor in trying to regulate it in the future they are being applauded to solve. Further research aimed at identifying the social-ecological impacts of drone fishing is needed and fisheries management agencies should aim to regulate the use of drones where necessary. While we acknowledge that the data collected in this review was based on internet search and social media activity, we contend that the observations made will have broad applicability to other countries where recreational drone fishing is gaining popularity. We have therefore developed several broad research and management recommendations which aim to maintain resilient coastal fisheries (see Table 2).

Acknowledgements We would like to thank specific members of the South Africa shore based recreational fishing community for approaching certain co-authors on this manuscript regarding their specific experience regarding the use of drones on South African beaches. We would also like to thank the various members of online social media groups who have started online conversations and attracted our interest in the topic and its potential social and ecological implications. Furthermore, we would like to thank the numerous commercial drone and aviation pilots that were approach and asked about their legal knowledge regarding the use of drones in South Africa.

\section{REFERENCES}

Arlinghaus, R. 2006. On the apparently striking disconnect between motivation and satisfaction in recreational fishing: The case of catch orientation of German Anglers. North American Journal of Fisheries Management 26: 592-605. https://doi.org/10.1577/ M04-220.1.

Arlinghaus, R., R. Tillner, and M. Bork. 2015. Explaining participation rates in recreational fishing across industrialised countries. 
Fisheries Management and Ecology 22: 45-55. https://doi.org/ 10.1111/fme.12075.

Anderson, J. 2021. Use of drones in fishing questioned. https:// northcoastcourier.co.za/166148/use-of-drones-in-fishingquestioned. Accessed February 25, 2021.

Aydin, B. 2019. Public acceptance of drones: Knowledge, attitudes, and practice. Technology in Society. https://doi.org/10.1016/j. techsoc.2019.101180.

Belhabib, D., P. Campredon, N. Lazar, U.R. Sumaila, B.C. Baye, E.A. Kane, and D. Pauly. 2016. Best for pleasure, not for business: Evaluating recreational marine fisheries in West Africa using unconventional sources of data. Palgrave Communications. https://doi.org/10.1057/palcomms.2015.50.

Barasona, J.A., M. Mulero-Pázmány, P. Acevedo, J.J. Negro, M.J. Torres, C. Gortázar, and J. Vicente. 2014. Unmanned aircraft systems for studying spatial abundance of ungulates: Relevance to spatial epidemiology. PLoS ONE 9: 12. https://doi.org/10. 1371/journal.pone.0115608.

Bennitt, E., H.L. Bartlam-Brooks, T.Y. Hubel, and A.M. Wilson. 2019. Terrestrial mammalian wildlife responses to Unmanned Aerial Systems approaches. Scientific Reports. https://doi.org/10. 1038/s41598-019-38610-x.

Bojabotseha, T.P. 2011. Dualism and the social formation of South Africa. African Journal of Hospitality, Tourism and Leisure 1 (3): $1-8$.

Borrelle, S.B., and A.T. Fletcher. 2017. Will drones reduce investigator disturbance to surface-nesting seabirds? Marine Ornithology 45: 89-94.

Branch, G.M., J. May, B. Roberts, E. Russell, and B.M. Clark. 2002. Case studies on the socio-economic characteristics and lifestyles of subsistence and informal fishers in South Africa. South African Journal of Marine Science 24: 439-462. https://doi.org/ 10.2989/025776102784528457.

Brownscombe, J.W., L.P. Griffin, T. Gagne, C.R. Haak, S.J. Cooke, and A.J. Danylchuk. 2015. Physiological stress and reflex impairment of recreationally angled bonefish in Puerto Rico. Environmental Biology of Fishes 98: 2287-2295. https://doi.org/ 10.1007/s10641-015-0444-y.

Brownscombe, J.W., A.J. Danylchuk, J.M. Chapman, L.F.G. Gutowsky, and S.J. Cooke. 2017. Best practices for catch-andrelease recreational fisheries - Angling tools and tactics. Fisheries Research 185: 693-705. https://doi.org/10.1016/j. fishres.2016.04.018.

Butcher, P.A., A.P. Colefax, R.A. Gorkin, S.M. Kajiura, N.A. López, J. Mourier, C.R. Purcell, G.B. Skomal, et al. 2021. The drone revolution of shark science: A review. Drones 5: 1-28. https:// doi.org/10.3390/drones5010008

Cherney M. 2019. Tackle box for the modern fisherman: rod, reel, drone. The Wall Street Journal. https://www.wsj.com/articles/ tackle-box-for-the-modern-fisherman-rod-reel-drone-

11574180033. Accessed February 25, 2021.

Cisneros-Montemayor, A.M., and U.R. Sumaila. 2010. A global estimate of benefits from ecosystem-based marine recreation: Potential impacts and implications for management. Journal of Bioeconomics 12: 245-268. https://doi.org/10.1007/s10818-0109092-7.

Cooke, S.J., and I.G. Cowx. 2004. The role of recreational fishing in global fish crises. Bioscience 54: 857-859. https://doi.org/10. 1641/0006-3568(2004)054\%5b0857:TRORFI\%5d2.0.CO;2.

Cooke, S.J., and C.D. Suski. 2005. Do we need species-specific guidelines for catch-and-release recreational angling to effectively conserve diverse fishery resources? Biodiversity and Conservation 14: 1195-1209. https://doi.org/10.1007/s10531004-7845-0.

Cooke, S.J., W.M. Twardek, R.J. Lennox, A.J. Zolderdo, S.D. Bower, L.F.G. Gutowsky, A.J. Danylchuk, R. Arlinghaus, et al. 2018.
The nexus of fun and nutrition: Recreational fishing is also about food. Fish and Fisheries 19: 201-224. https://doi.org/10.1111/ faf. 12246 .

Cooke, S.J., R.J. Lennox, B. Cantrell, and A.J. Danylchuk. 2020. Micro-fishing as an emerging form of recreational angling: research gaps and policy considerations. Fisheries. https://doi. org/10.1002/fsh.10487.

Cooke, S.J., P. Venturelli, W.M. Twardek, R.J. Lennox, J.W Brownscombe, C. Skov, K. Hyder, C.D. Suski, et al. 2021. Technological innovations in the recreational fishing sector: Implications for fisheries management and policy. Reviews in Fish Biology and Fisheries. https://doi.org/10.1007/s1160-02109643-1.

Danylchuk, S.E., A.J. Danylchuk, S.J. Cooke, T.L. Goldberg, J. Koppelman, and D.P. Philipp. 2007. Effects of recreational angling on the post-release behavior and predation of bonefish (Albula vulpes): The role of equilibrium status at the time of release. Journal of Experimental Biology and Ecology. 346: 127-133. https://doi.org/10.1016/j.jembe.2007.03.008.

da Silva, C., A.J. Booth, S.F.J. Dudley, S.E. Kerwath, S.J. Lamberth, R.W. Leslie, M.E. McCord, W.H.H. Sauer, et al. 2015. The current status and management of South Africa's chondrichthyan fisheries. African Journal of Marine Science 37: 233-248. https://doi.org/10.2989/1814232X.2015.1044471.

Derraik, J.G. 2002. The pollution of the marine environment by plastic debris: A review. Marine Pollution Bulletin 44: 842-852. https://doi.org/10.1016/S0025-326X(02)00220-5.

Erisman, B.E., L.G. Allen, J.T. Claisse, D.J. Pondella, E.F. Miller, and J.H. Murray. 2011. The illusion of plenty: Hyperstability masks collapses in two recreational fisheries that target fish spawning aggregations. Canadian Journal of Aquatic Science. 68: 1705-1716. https://doi.org/10.1139/f2011-090.

FAO. 2012. Recreational Fisheries. Technical Guidelines for Responsible Fisheries. No. 13. Rome, Italy: FAO. 176 pp.

FishingBooker. 2020. Drone Fishing - Is it really fishing? https:// fishingbooker.com/blog/drone-fishing-is-it-really-fishing. Accessed February 25, 2021.

Freudenberg, P., and R. Arlinghaus. 2009. Benefits and constraints of outdoor recreation for people with physical disabilities: Inferences from recreational fishing. Leisure Sciences 32 : 55-71. https://doi.org/10.1080/01490400903430889.

Gallagher, A.J., J.E. Serafy, S.J. Cooke, and N. Hammerschlag. 2014. Physiological stress response, reflex impairment, and survival of five sympatric shark species following experimental capture and release. Marine Ecology Progress Series 496: 207-218. https:// doi.org/10.3354/meps10490.

Gallagher, A.J., N. Hammerschlag, A.J. Danylchuk, and S.J. Cooke. 2017. Shark recreational fisheries: Status, challenges, and research needs. Ambio 46: 385-398. https://doi.org/10.1007/ s13280-016-0856-8.

Giglio, V.J., A.C. Suhett, C.S. Zapelini, A.S. Ramiro, and J.P. Quimbayo. 2020. Assessing captures of recreational spearfishing in Abrolhos reefs, Brazil, through social media. Regional Studies in Marine Science. https://doi.org/10.1016/j.rsma.2019.100995.

Giovos, I., I. Keramidas, C. Antoniou, A. Deidun, T. Font, P. Kleitou, J. Lloret, S. Matić-Skoko, et al. 2018. Identifying recreational fisheries in the Mediterranean Sea through social media. Fisheries Management and Ecology 25: 287-295. https://doi. org/10.1111/fme.12293.

Hambrecht, L., R.P. Brown, A.K. Piel, and S.A. Wich. 2019. Detecting 'poachers' with drones: Factors influencing the probability of detection with TIR and RGB imaging in miombo woodlands, Tanzania. Biological Conservation 233: 109-117. https://doi.org/10.1016/j.biocon.2019.02.017.

Harasti, D., K.A. Lee, C. Gallen, J.M. Hughes, and J. Stewart. 2015. Movements, home range and site fidelity of snapper 
(Chrysophrys auratus) within a temperate marine protected area. PLoS ONE 10: 11. https://doi.org/10.1371/journal.pone. 0142454.

Holder, P.E., L.P. Griffin, A.J. Adams, A.J. Danylchuk, S.J. Cooke, and J.W. Brownscombe. 2020. Stress, predators, and survival: Exploring permit (Trachinotus falcatus) catch-and-release fishing mortality in the Florida Keys. Journal of Experimental Biology and Ecology.. https://doi.org/10.1016/j.jembe.2019. 151289

Jiménez López, J., and M. Mulero-Pázmány. 2019. Drones for conservation in protected areas: Present and future. Drones 3: 10. https://doi.org/10.3390/drones3010010.

Kleiven, A.R., E. Moland, and U.R. Sumaila. 2020. No fear of bankruptcy: The innate self-subsidizing forces in recreational fishing. ICES Journal of Marine Science 77 (6): 2304-2307. https://doi.org/10.1093/icesjms/fsz128.

Knutsen, H., P.E. Jorde, J.A. Hutchings, J. Hemmer-Hansen, P. Grønkjær, K.E.M. Jørgensen, C. André, M. Sodeland, et al. 2018. Stable coexistence of genetically divergent Atlantic cod ecotypes at multiple spatial scales. Evolutionary Applications 11: 1527-1539. https://doi.org/10.1111/eva.12640.

Maggs, J.Q., B.Q. Mann, W.M. Potts, and S.W. Dunlop. 2016. Traditional management strategies fail to arrest a decline in the catch-per-unit-effort of an iconic marine recreational fishery species with evidence of hyperstability. Fisheries Management and Ecology 23: 187-199. https://doi.org/10.1111/fme.12125.

Mann, B. 2013. Southern African marine linefish species profiles. https://www.saambr.org.za/wp-content/uploads/2017/11/ Southern_African_Marine_Linefish_Species_Profiles.pdf. Accessed February 25, 2021.

Marine Living Resources Act. 1998. (MLRA) (Act No. 18 of 1998). The Republic of South Africa Government Gazette, South Africa 395 (18930). https://www.gov.za/documents/marine-livingresources-act-27-may-1998-0000. Accessed 31 Aug 2020.

Markowitz, E.M., M.C. Nisbet, A.J. Danylchuk, and S.I. Engelbourg. 2017. What's that buzzing noise? Public opinion on the use of drones for conservation science. BioScience 67: 382-385. https:// doi.org/10.1093/biosci/bix003.

Martin, D.R., B.M. Pracheil, J.A. DeBoer, G.R. Wilde, and K.L. Pope. 2012. Using the Internet to understand angler behavior in the information age. Fisheries 37: 458-463. https://doi.org/10. 1080/03632415.2012.722875.

Mitchell, J.D., D.L. McLean, S.P. Collin, S. Taylor, G. Jackson, R. Fisher, and T.J. Langlois. 2018. Quantifying shark depredation in a recreational fishery in the Ningaloo Marine Park and Exmouth Gulf, Western Australia. Marine Ecology Progress Series 587: 141-157. https://doi.org/10.3354/meps12412.

Monkman, G.G., M.J. Kaiser, and K. Hyder. 2018. Text and data mining of social media to map wildlife recreation activity. Biological Conservation 228: 89-99. https://doi.org/10.1016/j. biocon.2018.10.010.

Montero, P.F., and P.R. Lopez. 2012. IMO and the safety of fishing vessels: past, present and future. http://citeseerx.ist.psu.edu/ viewdoc/download?doi=10.1.1.569.3898\&rep=rep1\&type=pdf. Accessed February 25, 2021.

Moxham, E.J., P.D. Cowley, R.H. Bennett, and R.G. von Brandis. 2019. Movement and predation: A catch-and-release study on the acoustic tracking of bonefish in the Indian Ocean. Environemnatl Biology of Fishes. 102 (2): 365-381. https://doi.org/ 10.1007/s10641-019-00850-1.

National Environmental Management Act. 1998. (NEMA). The Republic of South Africa Government Gazette. Amendment No. 26025 (18/02/2004). https://www.environment.gov.za/sites/ default/files/legislations/nema_amendment_act57.pdf accessed 31 August 2020.
Nowak, M.M., K. Dziób, and P. Bogawski. 2019. Unmanned Aerial Vehicles (UAVs) in environmental biology: A review. European Journal of Ecology. 4: 56-74. https://doi.org/10.2478/eje-20180012 .

Oleksyn, S., L. Tosetto, V. Raoult, K.E. Joyce, and J.E. Williamson. 2020. Going batty: The challenges and opportunities of using drones to monitor the behaviour and habitat use of rays. Drones 2021: 12. https://doi.org/10.3390/drones5010012.

Penny, S.G., R.L. White, D.M. Scott, L. MacTavish, and A.P. Pernetta. 2019. Using drones and sirens to elicit avoidance behaviour in white rhinoceros as an anti-poaching tactic. Proceedings of the Royal Society B 286: 20191135. https://doi. org/10.1098/rspb.2019.1135.

Pauly D., and M. L. D. Palomares. 2010. An empirical equation to predict annual increases in fishing efficiency. Fisheries Centre Working Paper No. 7, University of British Columbia, Vancouver, $12 \mathrm{p}$.

Potts, W.M., N. Downey-Breedt, P. Obregon, K. Hyder, R. Bealey, and W.H. Sauer. 2019. What constitutes effective governance of recreational fisheries?-A global review. Fish and Fisheries 21: 91-103. https://doi.org/10.1111/faf.12417.

Potts, W.M., C. Attwood, P.D. Cowley, A.-R. Childs, A.C. Winkler, M.I. Duncan, T.S. Murray, B.Q. Mann, et al. 2020. Recommendations for the promotion of a resilient linefishery in the Anthropocene. African Journal of Marine Science 42: 255-267. https://doi.org/10.2989/1814232X.2020.1824738.

Proulx, R., P. Massicotte, and M. Pepino. 2014. Googling trends in conservation biology. Conservation Biology 28: 44-51. https:// doi.org/10.1111/cobi.12131.

Queiroz, N., N.E. Humphries, A. Couto, M. Vedor, I. Da Costa, A.M. Sequeira, G. Mucientes, A.M. Santos, et al. 2019. Global spatial risk assessment of sharks under the footprint of fisheries. Nature 572: 461-466. https://doi.org/10.1038/s41586-019-1444-4.

Rebolo-Ifrán, N., M.G. Grilli, and S.A. Lambertucci. 2019. Drones as a threat to wildlife: YouTube complements science in providing evidence about their effect. Environmental Conservation 46: 205-210. https://doi.org/10.1017/S0376892919000080.

Raby, G.D., J.R. Packer, A.J. Danylchuk, and S.J. Cooke. 2014. The understudied and underappreciated role of predation in the mortality of fish released from fishing gears. Fish and Fisheries 15: 489-505. https://doi.org/10.1111/faf.12033.

Rose, G.A., and D.W. Kulka. 1999. Hyperaggregation of fish and fisheries: How catch-per-unit-effort increased as the northern cod (Gadus morhua) declined. Canadian Journal of Aquatic Science. 56: 118-127. https://doi.org/10.1139/f99-207.

Ryan, P.G. 2018. Entanglement of birds in plastics and other synthetic materials. Marine Pollution Bulletin 135: 159-164. https://doi. org/10.1016/j.marpolbul.2018.06.057.

Sandbrook, C. 2015. The social implications of using drones for biodiversity conservation. Ambio 44: 636-647. https://doi.org/ 10.1007/s13280-015-0714-0.

Shea, M. R. 2014. The drone report: Do unmanned aerial systems have a place in hunting and fishing? Field and Stream. https:// www.fieldandstream.com/articles/hunting/2014/03/drone-reportdo-unmanned-aerial-systems-have-place-hunting-and-fishing. accessed February 25, 2021.

Skomal, G.B. 2007. Evaluating the physiological and physical consequences of capture on post-release survivorship in large pelagic fishes. Fisheries Management and Ecology 14: 81-89. https://doi.org/10.1111/j.1365-2400.2007.00528.x.

Spires, J. 2021. Drone fishing is turning aquatic refuges into popular fishing spots. https://dronedj.com/2021/02/24/drone-fishing-isturning-aquatic-refuges-into-popular-fishing-spots. Accessed February 25, 2021.

Stokes, D., K. Apps, P.A. Butcher, B. Weiler, H. Luke, and A.P. Colefax. 2020. Beach-user perceptions and attitudes towards 
drone surveillance as a shark-bite mitigation tool. Marine Policy 120: https://doi.org/10.1016/j.marpol.2020.104127.

Smith P.A. 2014. Drones pose special threat to outdoor ethics. Milwaukee Journal Sentinel. https://archive.jsonline.com/sports/ outdoors/drones-pose-special-threat-to-outdoors-ethicsb99185039z1-240381201.html. Accessed February 25, 2021.

Toivonen, T., V. Heikinheimo, C. Fink, A. Hausmann, T. Hiippala, O. Järv, H. Tenkanen, and E. Di Minin. 2019. Social media data for conservation science: A methodological overview. Biological Conservation 233: 298-315. https://doi.org/10.1016/j.biocon. 2019.01.023

Wang, Y., H. Xia, Y. Yao, and Y. Huang. 2016. Flying eyes and hidden controllers: A qualitative study of people's privacy perceptions of civilian drones in the US. Proceeding of Privacy Enhancing Technology 3: 172-190. https://doi.org/10.1515/ popets-2016-0022.

Wilde, G.R., and K.L. Pope. 2013. Worldwide trends in fishing interest indicated by internet search volume. Fisheries Management and Ecology 20: 211-222. https://doi.org/10.1111/fme. 12009.

Winker, H., S. Kerwath, C. Attwood, C. da Silva, J. Maggs, and D. Parker. 2017. The 2017 assessment of Silver kob (Argyrosomus inodorus) for the South African linefishery. FISHERIES/LSWG/ 2017/04. Cape Town: Department of Agriculture, Forestry and Fisheries.

Wolinsky, H. 2017. Biology goes in the air: Unmanned aerial vehicles offer biologists an efficient tool for observation and sampling from a safe distance. EMBO Reports 18: 1284-1289. https://doi. org/10.15252/embr.201744740.

Wortmann, J., M.F. O’Neill, W. Sumpton, M.J. Campbell, and J. Stewart. 2018. Stock assessment of Australian east coast snapper, Chrysophrys auratus Predictions of stock status and reference points for 2016. State of Queensland: Technical report.

Yoshikawa, T., and K. Asoh. 2004. Entanglement of monofilament fishing lines and coral death. Biological Conservation 117: 557-560. https://doi.org/10.1016/j.biocon.2003.09.025.

Publisher's Note Springer Nature remains neutral with regard to jurisdictional claims in published maps and institutional affiliations.

\section{AUTHOR BIOGRAPHIES}

Alexander C. Winkler $(\bowtie)$ is currently a Junior researcher at the Centro de Ciências do Mar (CCMAR), in Faro Portugal and an honorary research associate at Rhodes University, Makhanda, South
Africa where he conducted his $\mathrm{PhD}$ research. His research interests include Fish Biology, Migration Ecology and Recreational Fisheries. Address: Centro de Ciências do Mar (CCMAR), University of the Algarve, Faro, Portugal.

Address: Department of Ichthyology and Fisheries Science, Rhodes University, Makhanda, South Africa.

e-mail: alexwinkrsa@gmail.com acwinkler@ualg.pt awinkler@ru. ac.za

Edward C. Butler is a Post-doctoral fellow at the Department of Ichthyology and Fisheries Science, Rhodes University, Makhanda, South Africa. His research interests include Socio-Ecological Systems, Recreational Fisheries, Fish Biology

Address: Department of Ichthyology and Fisheries Science, Rhodes University, Makhanda, South Africa.

e-mail: e.butler@ru.ac.za

Colin G. Attwood is an Associate Professor at the Biological Sciences Department, University of Cape Town, Cape Town, South Africa his research interests include Fisheries Monitoring and Assessment, Recreational Fisheries, Fish Biology

Address: Biological Sciences Department, University of Cape Town, Cape Town, South Africa.

e-mail: Colin.Attwood@uct.ac.za

Bruce Q. Mann is a Senior Scientist at the Oceanographic Research Institute, South African Association for Marine Biological Research, Durban, South Africa his research interests include Recreational Fisheries, Fish Biology, Fish Movement, Marine Protected Areas Address: South African Association for Marine Biological Research, Durban, South Africa.

e-mail: bruce@ori.org.za

Warren M. Potts is a Professor at the Department of Ichthyology and Fisheries Science, Rhodes University, Makhanda, South Africa his research interests include Recreational Fisheries, Fish Biology, Fish Movement, Climate Change

Address: Department of Ichthyology and Fisheries Science, Rhodes University, Makhanda, South Africa.

e-mail: w.potts@ru.ac.za 